NEWS

\title{
The code within the code
}

\author{
Computational biologists grapple with RNA's complexity.
}

One of the most beautiful aspects of the genetic code is its simplicity: three letters of DNA combine in 64 different ways, easily spelled out in a handy table, to encode the 20 standard amino acids that combine to form a protein.

But between DNA and proteins comes RNA, and an expanding realm of complexity. RNA is a shape-shifter, sometimes carrying genetic messages and sometimes regulating them, adopting a multitude of structures that can affect its function. In a paper published in this issue (see page 53 ), a team of researchers led by Benjamin Blencowe and Brendan Frey of
"The splicing code is a problem that we've been bashing our heads against for years." the RNA landscape. In addition to understanding alternative splicing, informatics is helping researchers to predict RNA structures, and to identify the targets of small regulatory snippets of RNA that do not encode protein. "It's an exciting time," says Christopher Burge, a computational biologist at the Massachusetts Institute of Technology in Cambridge. "There's going to be a lot of progress in the next few years."

The floodgates were opened by high-throughput technologies that allow researchers to compile comprehensive catalogues of RNA molecules found in various tissues and the University of Toronto in Ontario, Canada, reports the first attempt to define a second genetic code: one that predicts how segments of messenger RNA transcribed from a given gene can be mixed and matched to yield multiple products in different tissues, a process called alternative splicing. This time there is no simple table - in its place are algorithms that combine more than 200 different features of DNA with predictions of RNA structure.

The work highlights the rapid progress that computational methods have made in modelling under different environmental conditions. Such techniques revealed that $95 \%$ of the human genome is alternatively spliced, and that changes in this process accompany many diseases. But no one knew how to predict which form of a particular gene would be expressed in a given tissue. "The splicing code is a problem that we've been bashing our heads against for years," says Burge. "Now we finally have the technologies we need."

Blencowe and Frey's team used the masses of data generated by these technologies to train a computer algorithm to predict the outcome of alternative splicing in mice. Given the DNA sequence of a particular gene, the algorithm predicts which segments of that DNA sequence will be included in a final messenger RNA molecule in one of four tissue types: the central nervous system, muscle, the digestive system and embryos. The model works well, says Burge, and is an important technological advance. But he hopes that it will be refined to mimic more closely the mechanism that the cellular splicing machinery uses to make its choices.

\section{Wiggle and jiggle}

The sequence of letters in an RNA molecule is not the only determinant of how the molecule will function. Its three-dimensional structure can also affect how it interacts with other molecules, including drugs that are designed to target it. "RNA forms highly flexible structures that wiggle and jiggle just due to thermal motion," says Hashim Al-Hashimi, a biophysicist at the University of Michigan in Ann Arbor. "It is very difficult to define them as a static structure." Structures of the same molecule determined using various techniques sometimes look wildly different,

\section{Nurse wants elite UK science focus}

Less than 24 hours after being nominated as the new president of the Royal Society - Britain's national academy of science Paul Nurse had already kicked off a controversy. In an interview published on 27 April in the British newspaper The Times, he argued for a more elitist approach to the funding of science. "You need a combination of special systems that attract and support those who are excellent," he said, "and rigorous reviews so that when they cease to be excellent, as many often are, they don't just hang on to those resources."

The interview (conducted before his nomination) riled many scientists in Britain, who are suspicious of concentrating limited resources on a few leading lights at the expense of the many. Nurse now says that his comments were not meant as an attack on the system as a whole. "The words didn't come out quite right," he says, before adding: "I do think there's a need to think about how one supports the very best science, which might need to be dealt with a little bit differently from the rest."

Speaking frankly is nothing new for the 61-year-old Nobel prizewinner. "Paul's quite opinionated," says Antony Carr, a biochemist at the University of Sussex, in Brighton, UK, who was a graduate student with Nurse in the mid-1980s. "Our lab meetings were fun but also a bit daunting at times," Carr recalls. "You were just waiting for him to tell you how it really was." "He can be kind of intense sometimes," adds Emily Nurse, one of his two daughters and a high-energy physicist at University College London. In earlier years, she says, she and her sister received many lectures on topics ranging from science to history. "I've never known anyone to be so interested in things," she says.

Born into a working-class family, Nurse's straight talking and sharp scientific skills eventually won him the chair at the University of Oxford's department of microbiology in 1988. He took charge of the Imperial Cancer Research Fund in London in 1996, steering the fund through its $\mathbf{2 0 0 2}$ merger with another charity,

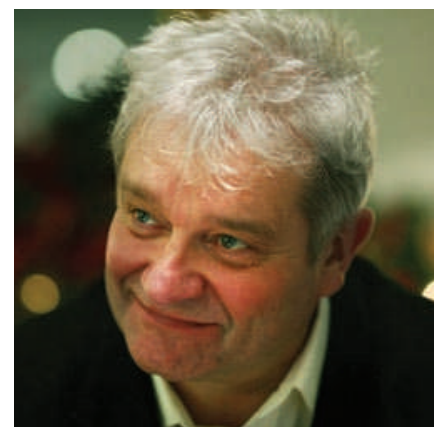

Paul Nurse has been nominated to be the next president of Britain's Royal Society.

the Cancer Research Campaign, into Cancer Research UK. Nurse was convinced that the charities would work better together than as competitors, and persuaded nervous scientists in both that the merger would be a success. In 2001, he shared the Nobel Prize for Physiology or Medicine for his 
